\title{
Role of Ultrasound guided Fine needle Aspiration in diagnosis of liver mass lesion
}

\author{
Ranu Tiwari Mishra ${ }^{1}$, Rashmi Nayak ${ }^{2}$,Pushpa Batham ${ }^{3}$ \\ ${ }^{1,2,3}$ Associate professor Department of Pathology, N.S.C.B Medical College, Jabalpur(M.P), India
}

Corresponding author: Dr. Rashmi Nayak, Associate Professor, Department of pathology, N.S.C.B Govt. Medical College, Jabalpur(M.P) Email: drrashminayak007@gmail.com

\begin{abstract}
Fine Needle Aspiration of the liver is a simpler technique and is reported to yield higher positivity in patients with hepatic malignancy as compared to core biopsy. Fine needle aspiration cytology has the advantage of causing significant less discomfort and a very low risk of complication. Of all the radiological procedures the ultrasound is most suited for fine needle aspiration cytology as real time images can be obtained and it prevents the perforation of gall bladder, colon and blood vessels, Ultrasound has higher level of practicality, requires no ionizing radiation and is widely applicable as compare to computerised tomography scan. Aim of the present study is to establish role of Ultrasound guided Fine Needle Aspiration in diagnosis of liver mass lesions.
\end{abstract}

Methods : We have performed UGS guided FNAC on 42 suspected cases of liver mass lesion. Detail history, clinical examination was done and consent was taken from patient after explaining the procedure to them. Bleeding time, Clotting time and Prothrombin time were done prior to procedure. All patients with liver mass lesion diagnosed on radiology were included in the study. Under all aseptic precaution Ultrasound guided FNAC was done from liver mass lesion using 26 gauge lumbar puncture needle. The material obtained in the needle was expelled onto glass slide and smear was made by opposition technique.

Results: Of 42 aspirates from liver, 13 were diagnosed as hepatocellular carcinoma, 23 were diagnosed as metastatic carcinomas. Attempt of grading and study of cellular patterns was done in hepatocellular carcinoma. Of 23 cases of metastatic carcinoma, in 11 cases primary site could be demonstrated. In 12 cases primary site could not be determined. 18 were adenocarcinomas and 5 were undifferentiated anaplastic carcinoma.

Conclusion: Ultrasound guided Fine Needle Aspiration of liver mass is safe, cost effective technique in localizing Liver lesion and acquiring adequate material for preoperative diagnosis of mass lesion of liver.

Keywords: NAC, Ultrasound guided FNAC, liver mass Introduction

Malignancy of the liver, either primary or secondary is one of the commonly occurring neoplasm in the body. Clinical findings, liver function tests and other investigations like ultrasound, CT scan are suggestive of liver neoplasia but unfortunately it has been shown that there is no clear relationship between the various echopatterns and primary sites of tumour origin. So tissue diagnosis is necessary for final confirmation. Needle biopsy of the liver using Vim Silverman needle was a widely used method of investigation in these patients, However the yield of positive diagnosis with a blind ${ }^{[1]}$ biopsy is low it varies from 50-71\% (Conn and Yesner, 1963, Ovelisen and Adbem 1970) and a complication rate of $10 \%($ major and minor complications,

Fine Needle Aspiration of the liver is a simpler technique and is reported to yield higher positivity in patients with hepatic malignancy as compare to core biopsy (Rasmussen et al 1972, Zornoza et al, 1980, Whitlatch et al 1984) ${ }^{[2,3,4]}$. Disadvantage of conventional blind procedure is that liver tissue is sampled from limited single area without radiologic guidance so focal abnormality can be missed, but fine needle aspiration cytology overcomes several of these limitations. Although the volume of tissue removed by FNAC aspiration cytology is only about one-tenth of a thick needle biopsy but it represents a better sampling of the liver since cells and tissue fragments are removed from a large area of liver as the needle is moved up and down during the aspiration. Fine needle aspiration cytology has the advantage of causing significant less discomfort and a very low risk of complication. As opposed to large core biopsy fine needle aspiration cytology can be taken from both left and right lobe and from either superficial or deep lesion, even in jaundiced patients. Another advantage of FNAC is that cytological smear can be stained and checked immediately and the biopsy can be repeated from more representative sites until a satisfactory sample has been obtained without undue risk to the patients. Of all the radiological procedures the ultrasound is most suited for fine needle aspiration cytology as real time images can be obtained and it prevents the perforation of gall bladder, colon and blood vessels, Ultrasound has higher level of practicality, requires no ionizing radiation and is widely applicable as compare to computerised tomography scan. Aim of the present study is to establish role of Ultrasound guided Fine Needle Aspiration in diagnosis of liver mass lesions.

Method- We have performed UGS guided FNAC on 42 suspected cases of liver mass lesion. Detail history, clinical 
examination was done and consent was taken from patient after explaining the procedure to them. Bleeding time, Clotting time and Prothrombin time were done prior to procedure. All patients with liver mass lesion diagnosed on radiology were included in the study. Under all aseptic precaution Ultrasound guided FNAC was done from liver mass lesion using 26 gauge lumbar puncture needle. The material obtained in the needle was expelled onto glass slide and smear was made by opposition technique. Smears prepared so were fixed in $95 \%$ alcohol for at least 30 min before staining. Stains used for FNAC smears were H\&E and Papanicolaou's stain.

Result-

Table 1. Cytological diagnosis in liver aspirate

\begin{tabular}{|c|l|c|c|}
\hline Age & & $\begin{array}{c}\text { USG } \\
\text { diagnosis }\end{array}$ & $\begin{array}{c}\text { Cytological } \\
\text { diagnosis }\end{array}$ \\
\hline 1 & Neoplastic & & \\
\hline & a) Benign & 2 & 2 \\
\hline & b) HCC & 15 & 13 \\
\hline & c) secondaries & 21 & 23 \\
\hline 2 & Inflammatory & 2 & 2 \\
\hline Total & Inconclusive & 2 & 42 \\
\hline
\end{tabular}

Total number of liver aspirate was 42 out of this 38 cases were neoplastic, 2 were inflammatory and in 2 cases were inconclusive on ultrasound. 36 cases out of 38 neoplastic cases( diagnosed clinically and radiologically) were malignant and cytological pictures showed malignant cells in all 36 cases., Out of 38 neoplastic cases ( on ultrasound) Cytological diagnosis was metastatic in 23 cases and primary liver cell carcinoma in 13 cases and remaining 2 cases were suggestive of benign cystic lesion. Out of 42 cases 2 cases were of liver abscess on ultrasonographically and FNAC also demonstrate inflammatory cells and necrotic debris. In all cases ultrasonography finding correlated well with cytological finding except in 4 cases. In 3 cases of secondaries ultrasonography suggested Hepatocellular carcinoma and in one case of Hepatocellular carcinoma ultrasound suggested the metastasis in liver.

Table 2 Metastatic tumour of Liver

\begin{tabular}{|l|c|c|c|}
\hline \multicolumn{1}{|c|}{$\begin{array}{c}\text { Secondaries } \\
\text { in liver. }\end{array}$} & $\begin{array}{c}\text { Total } \\
\text { cases }\end{array}$ & Male & Female \\
\hline 1. Adenocarcinoma & 18 & 12 & 6 \\
\hline $\begin{array}{l}\text { 2. Poorly differenti- } \\
\text { ated/ Anaplastic } \\
\text { carcinoma }\end{array}$ & 5 & 3 & 2 \\
\hline
\end{tabular}

Out of 23 cases of secondaries in liver 18 were adenocarcinoma and 5 were poorly differentiated/ anaplastic carcinoma

Table 3. Sex distribution of metastatic tumour of liver

\begin{tabular}{|l|c|c|c|}
\hline \multicolumn{1}{|c|}{ Primary site } & $\begin{array}{c}\text { Total } \\
\text { cases }\end{array}$ & Male & Female \\
\hline 1. Stomach & 4 & 4 & - \\
\hline 2. Gallbladder & 3 & 2 & 1 \\
\hline 3. Ovary & 3 & - & 3 \\
\hline $\begin{array}{l}\text { 4. Breast } \\
\text { 5. Primary site not }\end{array}$ & 12 & 9 & 1 \\
\hline kotal & 23 & 15 & 8 \\
\hline
\end{tabular}

Total of 23 cases of metastatic tumour were encountered, out of 42 cases of liver malignancies. Attempt was made to identify the primary site of lesion considering clinical history, radiological findings and cytological features of these 23 cases; 4 cases arose from carcinoma of stomach, 3 cases from carcinoma gallbladder, 3 cases from carcinoma of ovary, 1 case from carcinoma breast. In 12 cases of liver metastasis primary site could not be demonstrated.

\section{Cellular pattern observed in aspirates of Hepatocellular carcinoma in the present study}

The aspirates from well differentiated type of Hepatocellular carcinoma shows rich cellularity and resemblance with hepatocyte was marked. The relatively uniform polygonal tumour cells have round, centrally placed nuclei, usually a single well developed nucleolus and well defined, granular cytoplasm. The nuclear- cytoplasmic ratio was higher than seen in normal hepatocytes. 8 cases were graded as well differentiated. In one case cohesive cell cluster are lined by sinusoidal endothelial cells.

In moderately differentiated cases, smear were cellular cohesive pattern was seen in combination with arborescent pattern. In cohesive pattern cells are arranged in clusters. Resemblance of tumour cells with hepatocyte was less but still evident. Nuclear-cytoplasmic ratio was further increased. The nuclei are round or oval and show moderate degree of variation in size and shape, with prominent nucleoli, cytoplasm was less abundant. 3 cases were graded as moderately differentiated Hepatocellular carcinoma.

In poorly differentiated hepatocellular carcinoma no definite pattern was seen but dispersed cells and occasional acinar arrangement was seen. Poorly differentiated Hepatocellular carcinoma cells show little similarity to normal hepatocytes. The nuclear cytoplasmic ratio was very high, with relative 
scanty cytoplasm. The nuclei were pleomorphic and hyperchromatic. 2 cases were graded as poorly differentiated Hepatocellular carcinoma.

\section{Discussion-}

In the present study 42 cases of liver aspirates 28 were Male(66.66\%) and 14 were Female(33.33\%). More number of male case were also reported by Zornoza et al (1980) $52.77 \%$ and Verma K.(1986) 61.57\% ${ }^{[5]}$.

In the present study malignant lesions in liver were more common and comprises of $85.7 \%$ cases. Our findings are in concordance with the study of Wee et al (1995) and Herszenye et al (1995)

In the present study 36 cases of liver malignancy were detected. Of these largest number cases were of metastasis. In various other studies also highest number of cases were of metastasis (, Verma K et al 1986; Whitlach et al 1984; Stewart et al 2002; Nautiyal et al 2004; Sidhalingreddy et al 2011; Adhikari et al 2010) ${ }^{[8,12]}$. However ,Swamy et al studied ultrasound guided FNAC of 72 cases of hepatic masses and found malignant lesions (68.06\%) more common than benign lesions (30.56\%). Among the malignant lesion majority of them were hepatocellular carcinomas (36.12\%) followed by metastatic adenocarcinomas (19.45\%).

Largest number of secondaries were from gastrointestinal tract in various studies(Whitlatch et al 1984; Tao et al 1984) ${ }^{[13]}$. While in our studies majority of cases primary could not be detected. The reason for large number of unknown primary in our study may be because majority of the patients were poor and cannot afford higher diagnostic modalities which are costly.

Out of 23 cases of metastasis in the present study, 18 were diagnosed as metastatic Adenocarcinoma and 5 were diagnosed as undifferentiated anaplastic carcinoma. Other studies also found adenocarcinoma as the most common metastatic tumor in Liver (Caroline B et al $1988^{[14]}$, Adhikari et al 2010).

In the present study total number of cases of malignancy were 38 , cytologically positive were 36 and diagnostic accuracy was $94.73 \%$. Verma K et al 1986 performed fine needle aspiration cytology in hepatic malignancy without any radiologic guidance with the diagnostic accuracy of $87.7 \%$. In the present study diagnostic accuracy is $94.73 \%$ with FNAC done under Ultrasound guidance. This shows that accuracy of fine needle aspiration cytology improves under radiological guidance.

\section{Conclusion -}

Ultrasound guided Fine Needle Aspiration of liver mass is safe ,cost effective technique in localizing Liver lesion and acquiring adequate material for preoperative diagnosis of lesion. Although definitive diagnosis is not possible in all cases but it help in categorizing the Liver mass into benign, malignant and inflammatory lesion which is helpful in deciding the management for mass lesion of liver .

\section{REFERENCES}

1. Conn Ho, Yensar R, A Re-evaluation of needle biopsy in diagnosis of metastatic cancer of the liver. Ann Intern Med. 1963 Jul;59:53-61. [PubMed] [Google Scholar]

2. Rasmussen SN, Holm HH, Kristensen JK, Barlebo $\mathrm{H}$. Ultrasonically-guided liver biopsy. Br Med J. 1972 May 27;2(5812):500-502. [PMC free article] [PubMed] [Google Scholar]

3. Zornoza J, Wallace S, Ordonez N, Lukeman J. Fine-needle aspiration biopsy of the liver. AJR Am J Roentgenol. 1980 Feb;134(2):331-334. [PubMed] [Google Scholar]

4. Whitlatch S, Nunez C, Pitlik DA. Fine needle aspiration biopsy of the liver. A study of 102 consecutive cases. Acta Cytologica. 1984;28:719-725. [PubMed] [Google Scholar]

5. Verma K et al: Fine needle aspiration cytology in diagnosis of hepatic malignancy: Indian Journal Cancer vol.23(2):p.112-116:1986

6. Wee A, Nilsson B, Cahn Widdle C. Fine needle aspiration biopsy of hepatocellular carcinoma, some unusual features. ActaCytol. 1991; 35:661-670.

7. Herszenyi L, Farinati F, Cecchetto A, Marafin C, de Maria N, Cardin R, Naccarato R. Fine-needle biopsy in focal liver lesions: the usefulness of a screening programme and the role of cytology and microhistology. Ital J Gastroenterol. 1995 Dec; 27(9):473-8.

8. Stewart CJR, Coldewey J., Stewart IS. Comparison of fine needle aspiration cytology and needle core biopsy in the diagnosis of radiologically detected abdominal lesions. J. Clin. Pathol.2002; 55: 93-97.

9. Nautiyal S., Mishra RK, Sharma SP., Routine and ultrasound guided FNAC of intra-abdominal lumps - A comparative study. Journal ofCytology 2004; 21(3):129132.

10. SidhalingReddy, Sainath K Andola: F.N.A.C. of Intraabdominal lesions: Journal of Clinical and Diagnostic Research. 2011; August 5(4): 758-765.

11. Swamy MC, Arathi C, Kodandaswamy C. Value of ultrasonography-guided fine needle aspiration cytology in the investigative sequence of hepatic lesions with an emphasis on hepatocellular carcinoma. J Cytol. 2011;28:178-84. [PMC free article] [PubMed] [Google Schola 
12. RC Adhikari, A Tuladhar, S Shrestha, SK Sharma: Deep Seated Thoracic \& Abdominal lesions: Usefulness of Ultrasound guided F.N.A.C., a 3 year experience: Nepal Med Coll J 2010. 12(1): 20-25.

13. Tao LC, Ho CS, McLoughlin MJ, Evans WK, Donat EE. Cytologic diagnosis of hepatocellular carcinoma by fineneedle aspiration biopsy. Cancer. 1984;53:547-552. [PubMed] [Google Scholar

14. Caroline Bognel, PhillippeRougier, Jerome Leclere, Pierre Duvillard, Paul Charpentier Michel Prade: Fine needle aspiration of Liver and Pancreas with Ultrasound guidance. Actacytol 1988; 32: 22-26.

How to cite this article : Mishra R, Nayak R, Batham P . Role of Ultrasound guided Fine needle Aspiration in diagnosis of liver mass lesion.. Perspectives in Medical Research 2020; 8(1):71-74

Sources of Support: Nil,Conflict of interest:None declared. 